\title{
A Critical Review on Socio-Economic Consideration in Nepalese Environmental Impact Assessment.
}

\author{
Anish Parajuli ${ }^{1}$, Tej Kumar Shrestha ${ }^{1,2^{*}}$, Sarita Lawaju ${ }^{1}$, Ganesh Paudel $^{3}$, Sebika Dhakal ${ }^{1}$, \\ Sandhya Manandhar ${ }^{1}$, Pankaj Gyawaly ${ }^{4}$, Lok Nath Ghimire ${ }^{5}$ \\ ${ }^{1}$ Lumbini Environmental Services Pvt. Ltd, Kathmandu, Nepal \\ ${ }^{2}$ Khwopa College, Bhaktapur, Nepal \\ ${ }^{3}$ Department of Forests and Soil Conservation, Kathmandu, Nepal \\ ${ }^{4}$ Nepal Agricultural Research Council, Lalitpur, Nepal \\ ${ }^{5}$ Ministry of Forests and Environment, Kathmandu, Nepal
}

\begin{abstract}
*Corresponding Author: Tej Kumar Shrestha, Lumbini Environmental Services Pvt. Ltd, Kathmandu, Nepal and Khwopa College, Bhaktapur, Nepal
\end{abstract}

\begin{abstract}
Nepal is in the pace of development to achieve goal of becoming a prosperous country. In such rapid development process negative impact of development activities on environment and society is inevitable. In the contemporary global development debate, sustainable development has been agreed as the common goal of every development effort. Sustainable development demands reducing the negative environmental impacts of development. EIA, which identify, predict, evaluate and mitigate the biophysical, social, and other relevant effects of development proposals promotes environmentally sound and sustainable development. This paper aims to analyze the performance of EIA reports in terms of socio-economic issues in Nepalese context. EIA reports of different 5 sectors viz. energy, health, road, forestry and industry/other sectors approved by MoPE in between 2005 to 2015 were reviewed using checklist.

Of the reviewed EIAs, energy and road sector showed high quality performance while only forestry sector showed low performance. 56\% EIA of energy sector and $75 \%$ of road sector performed high quality and $25 \%$ EIA of forestry sector showed low performance. $100 \%$ EIA of health and industry/other sectors performed medium quality. $92 \%$ of EIAs showed highest performance in mitigation measures and monitoring. The performance of $88 \%$ of EIAs in baseline information was ranked high, while $80 \%$ performed high in evaluation of significant impact and alternative analysis. Only 20\% EIAs performed high in impact identification while most sector $(52 \%)$ performed medium in this phase. None of sector performed lowest in baseline information, mitigation measures and monitoring. Overall assessment on socio-economic consideration showed that only $32 \%$ of EIA performed high quality, while $64 \%$ performed medium quality and $4 \%$ of EIA showed lowest performance.
\end{abstract}

Keywords: Environmental Impact Assessment, Socio-economic, Baseline, Mitigation, Performance

\section{INTRODUCTION}

Nepal enters into the federal state from a long unitary system of governance. With this changing governance system, there is high level of development aspiration and demand of people. Government of Nepal, Province and Local Government are planning to carry out development activities in an accelerating pace with the goal of high-level economic growth. In an era where global population growth continues to increase geometrically and development is inevitable (MEA, 2005), there has been a consensus to pursue sustainable development by harmonizing development with the environment (Glasson et al, 2012). One of the tools recommended in achieving the goal of sustainable development is Environmental Impact Assessment (EIA) (Jay et al, 2007). The effectiveness of EIA has been given great attention by EIA practitioners, academics and policy makers (Sandham and Pretorius, 2008) through examining the quality of EIA (Fuller, 1999; Cashmore et al, 2002).

In the development projects various types of development activities such as hydropower construction, transmission lines, roads, industries, etc. would be executed. The impact on bio-physical and socioeconomic environment would be increased. For addressing these impacts EIA is provisioned by 
legislation. Environment Protection Act 1997, and Environment Protection Regulation 1997, has made mandatory for conducting either Initial Environmental Examination (IEE) or EIA before any development activities are implemented.

EIA is a process of identifying, predicting, evaluating and mitigating the biophysical, social, and other relevant effects of development proposals prior to making decision and commitments (IAIA, 1999). It is a tool which help in decisions making about whether the project should go ahead (Morris, and Therivel, 2009). EIA is recognized internationally as a key tool to be used in guiding human beings on the path to sustainable development. Hence the ultimate purpose of EIA is to promote environmentally sound and sustainable development through the identification of appropriate enhancement and mitigation measures (UNEP, 2002). EIA must ensure that development proposals do not undermine critical resources and ecological functions or well-being, lifestyle and livelihood of the communities and people who depend on them (UNEP, 2002).

To date, EIA has not adequately addressed the cumulative effects of development so there is much work to be done to integrate the sustainability agenda with EIA (IEMA, 2004). Still there is gap that whether social issues are properly incorporated in EIAs or not. In Nepal there is an absence of a common methodology or criteria to assess environmental, social and economic aspects in an integrated form. The environment has important socio-economic factors which are included in an EIA process. Socio-economic impact is mainly centered on human population that will alter how people live, work and interact with each other (Modak and Biswas, 1999) and influence on human health and well-being (Newton, 1995). Socio-economic impact assessment in EIA ensures public participation and social analysis into the project design (World Bank, 1995). It mainly focuses on the positive impact to maximize social utility and development potential, and making sure that the development is acceptable to the community and promotes sustainability (Becker and Vanclay, 2003). This paper aims to analyze by reviewing the performance of EIA reports in terms of considering socio-economic issues in Nepalese context.

\section{METHODOLOGY}

EIA review can be a valuable tool because addressing the quality of EIA is of high importance to properly inform the public and the decision makers about the significant environmental effects of the project (Canelas et al. 2005). Five key sectors namely energy, health, road, forestry and industry/other were selected randomly (although purposively in some cases) for the review of the quality of 25 EIAs. The following methodology were employed in the study.

\subsection{Evaluation Checklist}

Impact analysis was based on evaluation checklist covering six review areas i.e. baseline information, impact identification, significance evaluation, alternative analysis, mitigation measures and monitoring as done by Shrestha, et al., 2017. Review criteria under each review area was developed based on the minimum legislative requirements by the EIA legislation of Nepal. Systematic and hierarchical structured framework of Lee and Colley (1992) EIA Review package of Lee et al., 1999 was used in the study due to its robustness, reliability and extensive use, which was further modified for this study using relevant literatures on socio-economic issues, Nepalese EIA legislation, and guidelines prepared by Ministry of Forests and Soil Conservation (MoFSC) (2002) for forestry sector. Reference from MoFSC (2002), Lee et al. (1999), Thompson et al. (1997) were used for developing of evaluation criteria under six review areas.

Seven evaluation criteria suggested by MoFSC 2002 were developed under baseline information which included description of socio-economic environments, land holding and settlement pattern, information on population, household and economic activities, status of education, health, sanitation, cast and ethnic composition, involvement of qualified professionals, and consultation with the concerned agencies and stakeholders in obtaining baseline information (Morris et al. 2009; Lee et al, 1999).

Impact identification had nine criteria which included clear description of the methods employed in identifying socio-economic impacts, land acquisition and compensation distribution, loss of agroproducts and agricultural impacts, labour force affecting social and economic conditions, identification of migrant families, relocated families, loss of community infrastructures \& facility, services and impact on gender, indigenous and vulnerable groups (Lee et al, 1999; MoFSC, 2002).

Under significance evaluation, five criteria were developed covering method used to determine significance of impact, criteria used in defining significance of impact (Thompson et al. 1997), 
documentation of summary of the potentially significant socio-economic impact (Lee et al, 1999), adequately addressing the national policies, international conventions and obligations and evaluation of significant socio-economic issues (Shrestha et al, 2017).

Alternative analysis included five criteria encompassing clear statement of impacts of the respective alternatives, technical and economic feasibility of considered alternatives, (Thompson et al. 1997), well explained rejection of each alternative, consideration of different sites, process, designs, scales, layouts and operating conditions in proposed project and provision of comparison with no action options with action option (Lee et al. 1999).

Mitigation measures covered twelve criteria which included specification of mitigation measures for potential significant impacts, detail description of means and time span of implementation of proposed measures, description of residual impacts of project, clear commitment to mitigation by the developer (Lee et al. 1999; Shrestha et al, 2017; Thompson et al., 1997), compliance with the legal requirements in acquiring land for temporary and permanent use, restoration measures for the families for the loss of agricultural lands and agro-products, compensation for affected families on loss of assets, specification of measures to uplift the economic condition and employment generation, capacity building of affected people, empowerment of women, indigenous and vulnerable groups, conflict resolution and reconstruction of community infrastructures/facility, services and resource (MoFSC, 2002).

Monitoring included four criteria covering monitoring and commitment, adequacy of monitoring programs for the social environmental components, relevant indicators for measurement of socioeconomic aspect during monitoring of construction and operation, adequacy of costs for the monitoring program presented in EMP for the socio-economic component (Lee et al. 1999; Shrestha et al,2017).

\subsection{Sample}

Twenty-five EIAs were randomly selected among 261 EIAs reports approved by MOPE (Ministry of Population and Environment) until $12^{\text {th }}$ October, 2016. EIAs were across five sectors: Energy, Health, Road, Forestry and industry/other sector where nine EIAs from energy sector and four each from health, road, forestry and industry/other sectors.

\subsection{Pilot Test}

A pilot test was conducted on two randomly selected EIA which were not part of the samples used for the study. This was used to identify areas of weaknesses such as for ambiguity or duplications in the draft evaluation checklist, which was corrected before subsequently using it for the final evaluation.

\subsection{Review Quality of EIA}

According Lee et al. 1999, once the review areas have been assessed, an assessment symbol and an overall judgment of the EIA must be assigned. Criteria mentioned for each EIA were evaluated and the outcome were assessed using Lee et al. 1999 assessment symbols. Each criterion was given with the grades (score) as applicable considering to the corresponding symbol explanation. Score value of 5 was assigned for Grade A that represented generally well performed, no important task left incomplete. Grade B which is generally satisfactory and complete, only minor omissions and inadequacies was valued score 4 . Grade $\mathrm{C}$ representing just satisfactory, despite omissions and/or inadequacies was valued score 3. Score value of 2 was assigned for Grade D that represented, parts are well attempted but must be considered just unsatisfactory. Score 1 was assigned for Grade E representing not satisfactory, significant omissions or inadequacies. Score 0 was assigned for Grade F representing very unsatisfactory, important task (s) poorly done or not attempted. NA represented not applicable which was assigned when the review topic was not applicable or it was irrelevant in the context.

\subsection{Data Analysis}

The review criteria were analyzed and the review grade were provided, then the reviewed report was evaluated with the overall appraisal of the report. Quality of EIAs were evaluated based on six review areas. Qualitative values suggested by Lee et al. 1999 was assigned to evaluate the overall quality of the project characteristics. Symbol A, B (>80\%) was assigned for high quality. Similarly, Symbol C, $\mathrm{D}(50$ to $<80)$ was assigned for medium quality and Symbol E, F $(<50)$ for low quality. 


\section{RESULTS}

\subsection{Overall Performance of EIAs by Sector}

Of the reviewed EIAs, energy and road sector showed high quality performance while only forestry sector performed low quality. 56\% energy sector and $75 \%$ road sector performed high quality and $25 \%$ forestry sector showed low performance (Figure 1). 100\% health and industry/other sector performed medium quality.

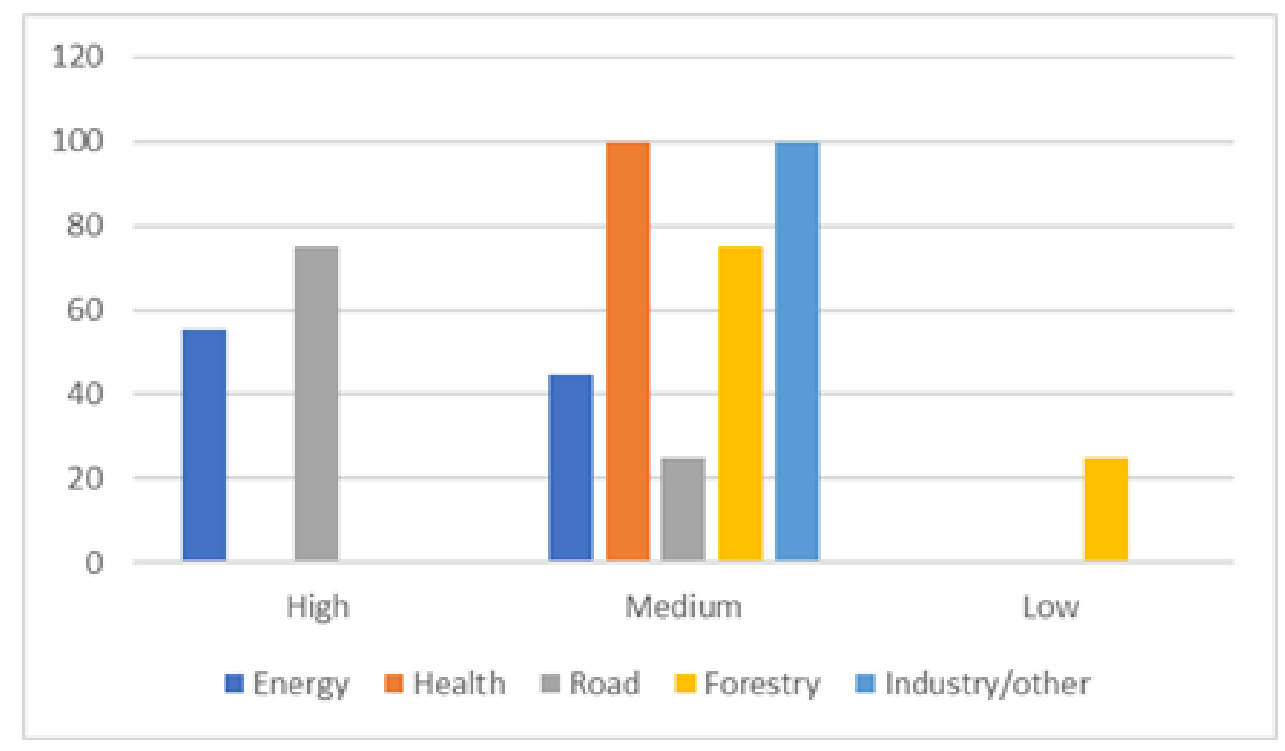

Figure1. Performance of EIA by Sector

\subsection{Variation in Baseline Information Performance by Sectors}

As shown in figure 2, most of the EIAs reviewed performed high quality in baseline information. None of the sector showed low performance during baseline information. $100 \%$ reviewed EIAs for energy, health and road sector performed high quality in baseline information. Majority i.e. $75 \%$ industry sector showed high performance while rest showed medium performance. In road sector both high and medium performance were seen equally.

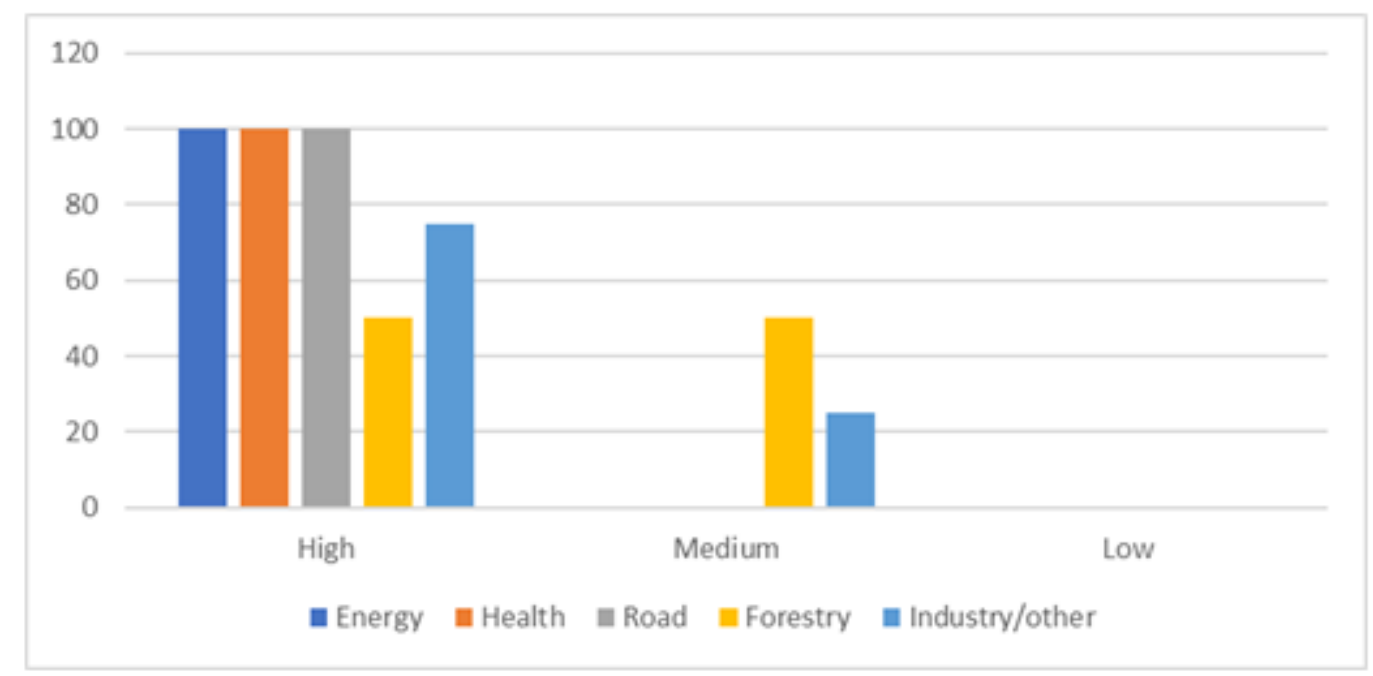

Figure2. Variation in Baseline Information Performance

\subsection{Variation in Impact Identification Performance by Sectors}

Figure 3 showed only energy and road sector showed high quality performance in impact identification phase. The performance of $78 \%$ of energy sector and $75 \%$ of road sector were found high while rest performed medium. Entire forestry sector performance was of low rank. In industry sector both high and medium performance were seen equally. Most of health sector performed medium while only $25 \%$ showed low performance in impact identification. 


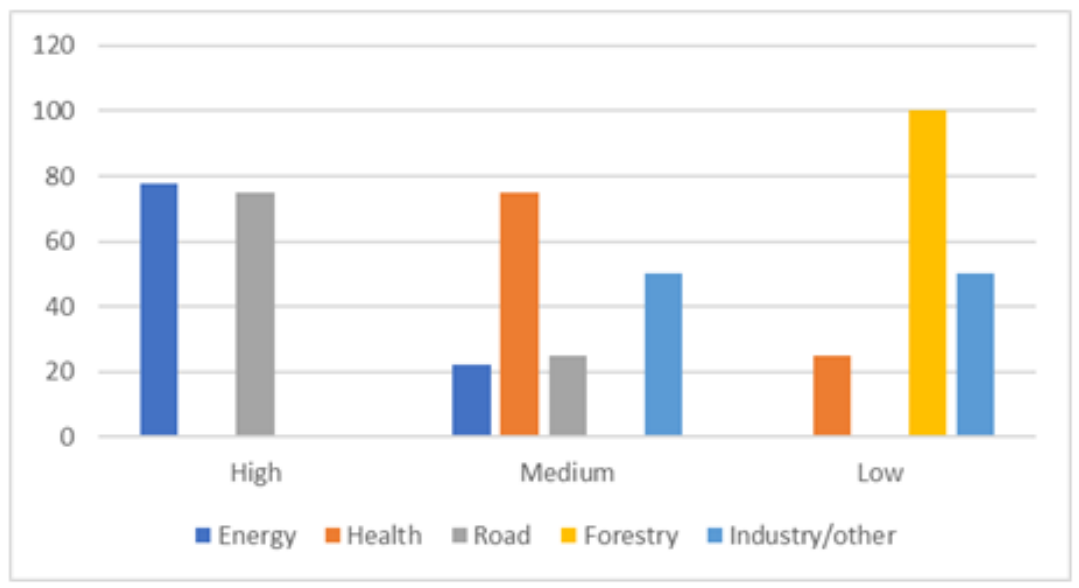

Figure3. Variation in Impact Identification Performance

\subsection{Variation in Evaluation of Significant Impacts Performance by Sectors}

Almost all sector showed high quality performance in evaluation of significant impacts. Entire health and industry/other sector performed high quality. $75 \%$ of EIAs reviewed from forestry sector performed high with $25 \%$ performing medium. Similarly, $75 \%$ of road sector showed highest performance with remaining 25\% performing low. Most of energy sector i.e. 76\% showed highest performance followed by low and medium performance by $22 \%$ and $11 \%$ respectively.

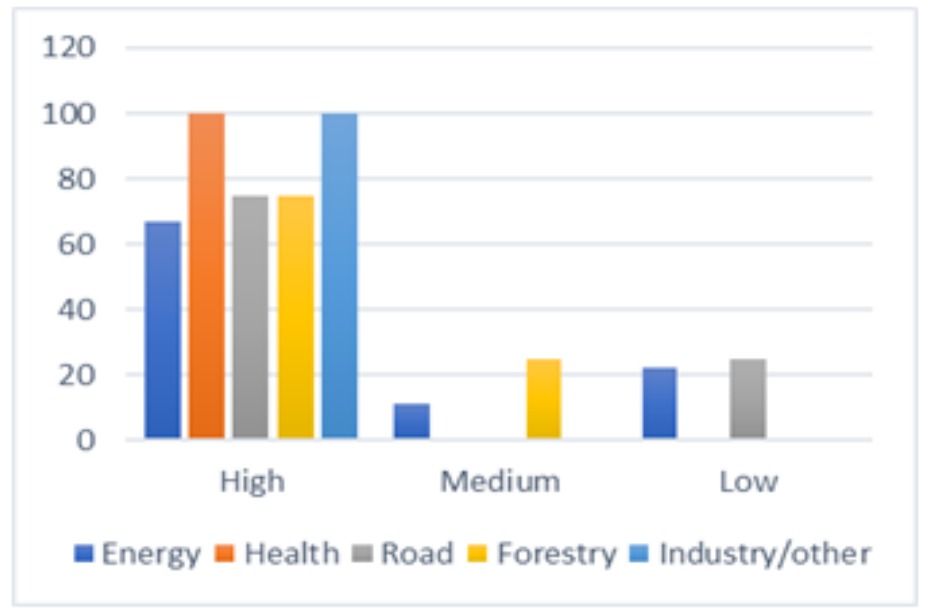

Figure4. Variation in Evaluation of Significant Impacts Performance

\subsection{Variation in Alternative Analysis Performance by Sectors}

The performance of entire sectors in alternative analysis is exactly like evaluation of significant impacts.

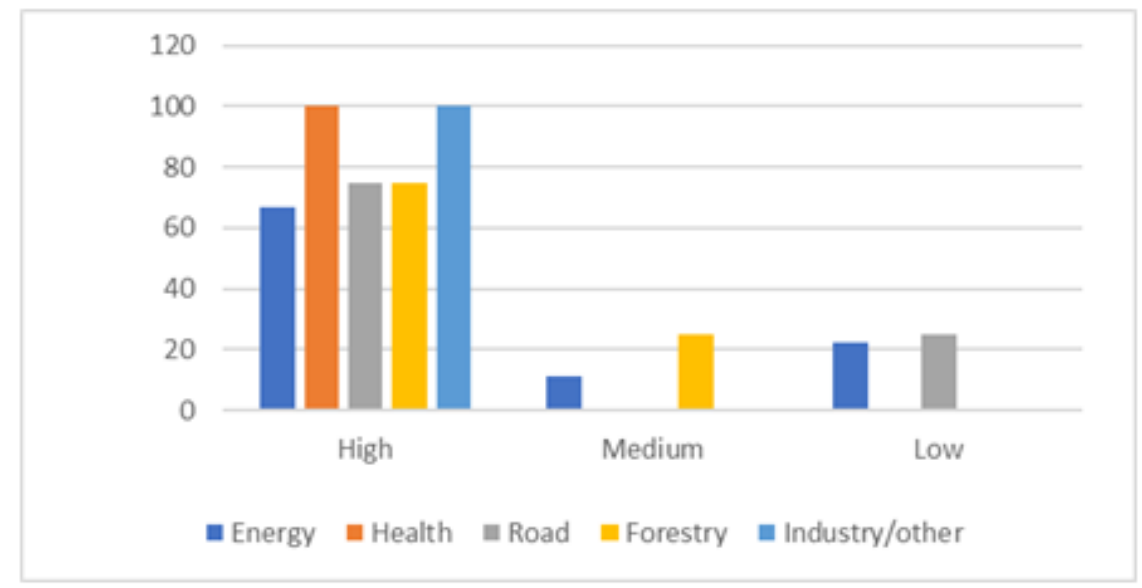

Figure5. Variation in Alternative Analysis Performance 


\subsection{Variation in Mitigation Measures Performance by Sectors}

The performance of entire EIAs in mitigation measures were found high ranked. Expect road sector all other sectors showed highest performance. Both high and medium performance was seen equally in road sector.

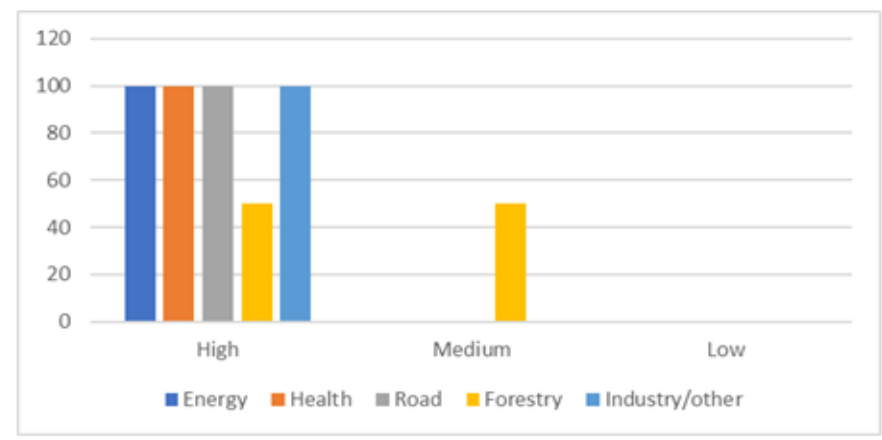

Figure6. Variation in Mitigation Measures Performance

\subsection{Variation in Monitoring Performance by Sectors}

The performance of EIAs was found to be satisfactory in monitoring with almost all sector performing highest quality. Entire health, road and industry/other sector showed highest performance. None of sector performed lowest in monitoring. $11 \%$ energy sector and $25 \%$ forestry sector performed medium.

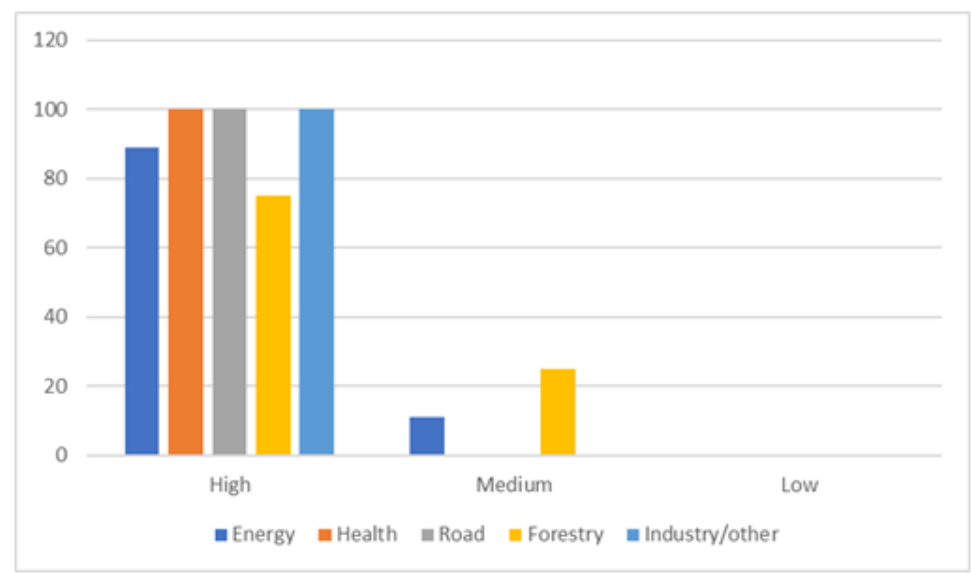

Figure7. Variation in Monitoring Performance

\subsection{Comparative Study of Social-Economic Issues in Different Phases}

The highest quality performance was seen in mitigation measures and monitoring accounting for $92 \%$ of EIAs. The performance of $88 \%$ of EIAs in baseline information was ranked high, while $80 \%$ performed high in evaluation of significant impact and alternative analysis. Only 20\% EIAs performed high in impact identification while most sector (52\%) performed medium in this phase. None of sector performed lowest in baseline information, mitigation measures and monitoring.

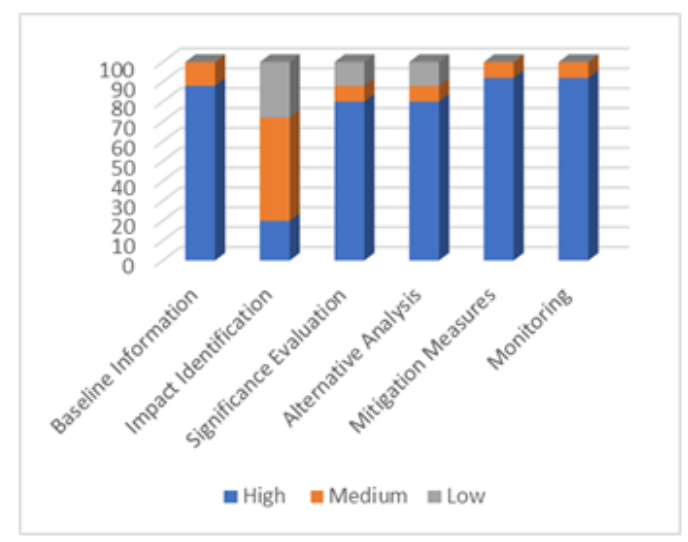

Figure8. Overall Performance of Review Areas in EIA 


\subsection{Overall Performance of EIA}

Overall assessment on socio-economic consideration showed that only 32\% of EIA performed high quality, while $64 \%$ performed medium quality and $4 \%$ of EIA showed lowest performance.

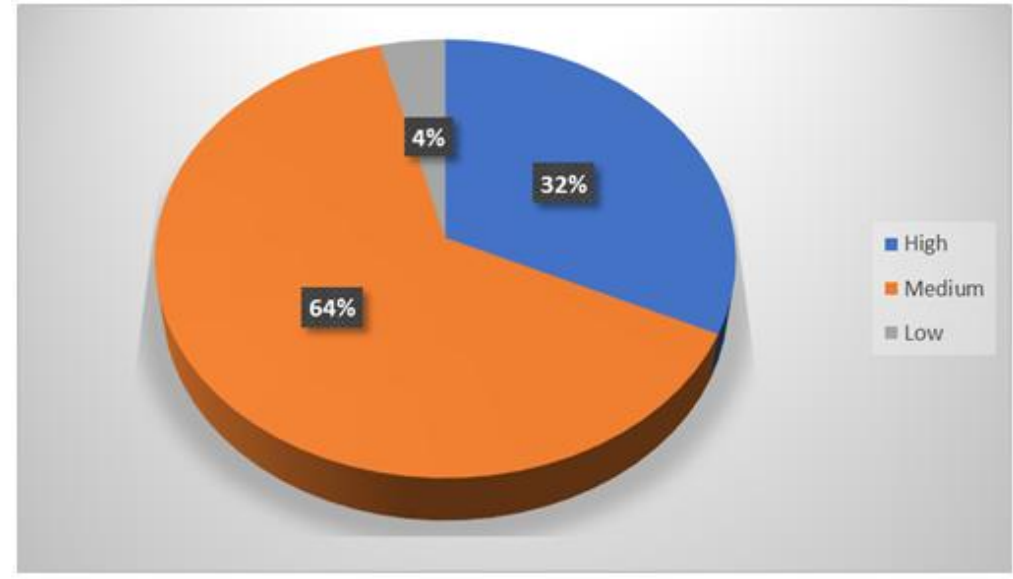

Figure9. Overall Performance of EIA in terms of consideration of socio-economic issues

\section{DISCUSSION}

\subsection{Quality of Eias From Different Sectors}

Of the reviewed EIAs, energy and road sector showed high quality performance while only forestry sector performed low quality. Due to the small sample for health, road, forestry and industry/other sector, the result needs to be interpreted with precaution. Energy sector has been practicing EIAs from the early development in Nepalese context. Sectoral guidelines with various improvements in EIAs report has been frequently conducted in this sector. The poor quality of the forestry sector might be attributable to the large land required for development activities. Magnitude of socio-economic impacts depend on size of development activities (Thompson et al. (1997) and Shrestha et al. (2017)). Due to the larger size of forestry developments, it may be difficult to adequately address the broad range and complexity of their associated socio-economic impact. As such, alternatives such as different locations are usually exempted from consideration.

\subsection{Comparative Study of Socio-Economic Issues in Different Phases of Eias}

In terms of the performance in individual phases of EIA, it was observed that mitigation and monitoring were the best performed stage while the worst performed stage was the impact identification.

\subsubsection{Baseline Information}

Review showed that most of the EIAs performed high quality for baseline information in terms of consideration of socio-economic issues. However, during the review various weakness in baseline information were identified. While existing socio-economic status was adequately provided by the reviewed EIAs, there was lack of detail information about the expertise involved in the baseline collection. According to Treweek (1996) and Shrestha et al. (2017), shorter time allocated for collection of baseline information influence the accuracy of the information provided. The main sources of baseline data were desk study, consultation and field survey, showing that socio-economic issues were obtained from reliable and robust sources. Review of EIA showed that public consultation was effectively complied as per the provision of Environmental Protection Act, 1997 and Environmental Protection Regulation, 1997. The performance of baseline information being satisfactory reflects that the legal compliance, rules and guidelines for this stage is clear and convenient to follow.

\subsubsection{Impact Identification}

Overall performance of EIAs in impact identification was low. Energy and road sector were the only sector which performed high quality in ranking. In entire sector weakness were observed in impact identification during identification of most affected families and impacts caused by relocated families on socio-economic conditions. 


\subsubsection{Significant Evaluation}

From this study, it was revealed that almost all sector showed high quality performance in evaluation of significant impacts. It was also observed that this step showed similarities with alternative analysis. Evaluation of significant impact follows impact identification and prediction (Glasson et al., 2012). Thus, the evaluation is always possible for impacts of their good impact identification.

\subsubsection{Alternative Analysis}

According to Environmental Assessment sourcebook (1996), alternatives analysis in Environmental Assessment is designed to bring environmental and social considerations into the "upstream" stages of development planning, project identification, site selection, design and implementation. Steinemann (2001) describes alternatives as the heart of the EIA and the quality of decisions depend on the robustness of selection of alternatives to choose from. Glasson et al. (2012) also emphasize the importance of alternatives in ensuring that all feasible approaches to a project are adequately considered and thus, contribute to preventing harm to the environment.

\subsubsection{Mitigation Measures}

As observed from the result, mitigation measure was the highest performed stage of the EIA. This was because most of the very important review criteria under mitigation were effectively addressed in all the reviewed reports. This implies that socio-economic issues were carefully considered while designing the mitigation measures. Without the incorporation of these issues' public would not be ready to pass the EIAs as people are concerned on socio-economic issues.

\subsubsection{Monitoring}

The performance of EIAs was found to be satisfactory in monitoring with almost all sector performing highest quality. Although most of the EIA discussed the monitoring types and mechanism, there was lack of monitoring commitment.

\subsection{Overall Quality of EIA}

From this study, it was observed that $4 \%$ EIA reviewed for consideration of socio-economic issue showed least performance. Majority (64\%) of EIAs performed medium quality while 32\% showed high quality performance. Thus, with slight improvement on some crucial areas of EIA this is expected to result into higher percentage of quality EIA in the country.

\section{CONCLUSION}

In the global era where development is inevitable, there is raising concerns to pursue sustainable development by harmonizing development with the environment. One of tools to achieve the goal of sustainable development is EIA. Based on sectoral performance, the percentage of reports believed medium for the EIA reviewed under each sector. It was found energy and road sector showed high quality performance while only forestry sector performed low quality.

In this study highest ranked performance were seen in mitigation measures and monitoring followed by baseline information, significant evaluation and alternative analysis. It was found that impact identification stage was the worst performed within the stages. None of sector performed lowest in baseline information, mitigation measures and monitoring.

In this study several inadequacies comparable to findings from past international studies were equally observed. For EIA to effectively act as a tool to aid sustainable development in the country, the identified inadequacies in this needs to be addressed with great commitment from the stakeholders involved in the process. Based on the findings of this study, the overall performance of the EIA considering socio-economic issues are moderate, showing that best practice in the EIA is yet to evolve in the country. With the bulk of the report assessed as medium quality, a bit of effort in addressing the observed inadequacies are expected to improve the quality in the country.

\section{REFERENCES}

[1] Becker, H.A. and Vanclay, F. (2003). The international Handbook of Social Impact Assessment. Cheltenham: Edward Elgar Publishing Limited.

[2] Canelas, L, P., Almansa, M., Merchan and Cifuentes, P. (2005). "Quality of Environmental Impact Assessments in Portugal and Spain”, Environmental Impact Assessment Review, 25, pages 217- 225. 
[3] Cashmore, M. E., Christophilopoulos, E. and Cobb, D. (2002). The quality of Environmental Impact Assessments in Thessaloniki, Greece. Journal of Environmental Assessment Policy and Management, 4(4), 371-395.

[4] Environmental Assessment sourcebook. (1996). Alternatives analysis in EA is designed to bring environmental and social considerations into the "upstream" stages of development planning project. In T. w. bank, Environmental Assessment sourcebook update.

[5] Fuller, K. (1999). Quality and quality control in environmental impact assessment. In: Handbook of Environmental Impact Assessment, Vol. 2. Environmental Impact Assessment in Practice: Impact and Limitations, ed. J Petts. Oxford: Blackwell, 55-82.

[6] Glasson, J., Therivel, R., Chadwick, A. (2012). Introduction to environmental impact assessment. 4th Edition. Oxon: Routledge.

[7] IEMA (Institute of Environmental Management and Assessment) (2004). Guidelines for Environmental Impact Assessment.

[8] International Association for Impact Assessment (IAIA) (1999). Principles of Environmental Impact Assessment Best Practice. Institute for Environmental Assessment. Fargo, United States and Lincoln, United Kingdom.

[9] Jay, S., Jones, C., Slinn, P., Wood, C. (2007). Environmental Impact Assessment: T=Retrospect and prospet. Environmental Impact Assessment Review, 27(\$), 287-300.

[10] Lee, N. \& Colley, R., 1992. Reviewing the quality of environmental statements Occasiona N. and Colley, R. (1992). Reviewing the quality of environmental statements Occasional Manchester: EIA Centre. Department of planning and landscape. University of Manchester.

[11] Lee, N., Colley, R., Bonde J. and Simpson, J. (1999). Reviewing the quality of environmental statements and environmental appraisals. Occasional Paper 55. EIA Centre, Department of Planning and Landscape, University of Manchester.

[12] Manchester: EIA Center.a

[13] Millennium Ecosystem Assessment (2005). Ecosystems and human well-being: Synthesis. Washington, DC: Island Press.

[14] Ministry of Forest and Soil Conservation (MoFSC) (2002). Guidelines for Review of Initial Environmental Examination and Environmental Impact Assessment of Forestry Sector., Singhadurbar, Kathmandu, Nepal.

[15] Modak P. \& Biswas A. K., (1999). Conducting Environmental Impact Assessment for Developing Countries, United Nations University press.

[16] Morris, P, \& Therivel, R., (2009). Methods of Environmental Impact Assessment, $3^{\text {rd }}$ Edition, Routledge, Oxon.

[17] Newton, J. (1995). The integration of socio-economic impact in EIA and project appraisal. MSc dissertation, University of Manchester Institute of Science and Technology.

[18] Sandham, L. A. and Pretorins, H. M. (2008). A Review of EIA report quality in the North West province of South Africa. Environmental Impact Assessment Review, 28(4-5), 229-240.

[19] Shrestha, T. K., Manadhar, S., Paudel, G., Parajuli, A., Baral, S. R., Koirala, A., \& Shrestha, S. (2017). Reviewing Biological Consideration in Nepalese Environmental Impact Assessment. International Journal of Innovative Research in Science, Engineering and Technology 6(7):1247-12488.

[20] Steinemann, A. (2001). Improving alternatives for environmental Impact Assessment. Environ Impact Assess Rev, 21(1), 3-21

[21] Thompson, S., Treweek, J. R., Thurling, D. J., (1997). The ecological component of Environmental Impact Assessment: a critical review of British Environmental Statements. Journal of Environmental Planning and Management, 40:157-171, 1997.

[22] Treweek, J. (1996), Ecology and environmental assessment. Journal of Applied Ecology, 33:191-199

[23] UNEP (2002). UNEP EIA Training Resource Manual, United Nations Environment Programme (UNEP), Geneva.

[24] World Bank. (1995). Social Assessment Environment Department Dissemination Notes, Number 36, Washington DC: World Bank.

Citation: Tej Kumar Shrestha, et.al, " A Critical Review on Socio-Economic Consideration in Nepalese Environmental Impact Assessment.", International Journal of Research in Environmental Science (IJRES), vol. 5, no. 4, pp. 11-19, 2019. Available: DOI: http://dx.doi.org/10.20431/2454-9444.0504002

Copyright: (C) 2019 Authors. This is an open-access article distributed under the terms of the Creative Commons Attribution License, which permits unrestricted use, distribution, and reproduction in any medium, provided the original author and source are credited. 